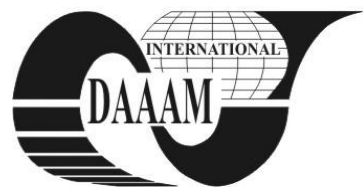

Annals of DAAAM for 2011 \& Proceedings of the 22nd International DAAAM Symposium, Volume 22, No. 1, ISSN 1726-9679 ISBN 978-3-901509-83-4, Editor B. Katalinic, Published by DAAAM International, Vienna, Austria, EU, 2011 Make Harmony between Technology and Nature, and Your Mind will Fly Free as a Bird

\title{
PHYSICAL MODELING AND SIMULATION OF MECHATRONICS SYSTEMS BY ACAUSAL BOND GRAPHS
}

\author{
DAMIC, V[jekoslav]; COHODAR, M[aida] \& KULENOVIC, M[alik]
}

\begin{abstract}
Modeling of complex mechatronics systems consisting of subsystems from different physical domains and interacting by power exchange requires a systematic multidisciplinary approach. This paper presents how model of such complex real systems can be effectively developed using acausal bond graphs. The focus is devoted to describing a systematic procedure for building model based on component model approach. The bond graph models can be developed as a tree of component models. The mathematical model is generated in the form of a system of differential-algebraic equations (DAEs) and solved using a suitable solver. Proposed approach is realized using integrated modeling and simulation environment of software BondSim. Two numerical examples are considered to confirm the efficiency of the described approach. Key words: mathematical modeling, object-oriented approach, differential-algebraic equations, bond graphs
\end{abstract}

\section{INTRODUCTION}

Modeling and simulation becomes a powerful tool in the product design. Today's trends in mechatronics lead to integration of electronics and computer control with mechanical subsystems. Engineering systems typically consist of components involving power interaction. In such contexts the bond graphs play important role, providing a sound basis for developing multi-domain models. They graphically represent the power flow through the system.

Painter's idea of the bond graphs were developed and applied by many researchers (Karnopp et al., 2000; Cohodar et al., 2009). This paper presents general methodology of modeling and simulation of complex engineering systems using bond graphs in acausal form (Damic \& Montgomery, 2003). An alternative approach could be based on Modelica language (Fritzson, 2004).

\section{COMPONENT MODEL APPROACH}

The essence of approach to modeling described in this paper is system decomposition and the concept of the component models. A component word model represents a component graphically by its name and ports (power and control). Ports are places at the component boundary where components interact with other components or environment. Components are joined by bond lines. The bond graphs enable systematic development of a model in form of a tree of the component models. The leaves of the tree are elementary components that model basic physical processes in a unique way in the system. There are nine elementary components:

- Inertial (I), Capacitive (C) and Resistive (R) components,

- Source Effort (SE) and Source Flow (SF),

- Transformers (TF) and Gyrators (GY),

- Efforts (1) and Flow junctions (0).

The elementary components are used to model basic physical processes based on suitable physical analogy. Each process is described by pairs of effort and flow variables, commonly termed the power variables, because their product is power delivered.

The modeling methodology is implemented as computer visual modeling environment BondSim (developed by the first author). It supports systematically model development and mathematical model is automatically generated using symbolic manipulation routines.

\section{GENERATION OF MATHEMATICAL MODEL}

In contrary to the common praxis in bond graphs, in the approach described here the causalities are not considered, following the praxis in other modeling languages such as Modelica, VHDL and others. The bond graph method is based on velocity formulation resulting in the mathematical models in the form of differential-algebraic equations (DAEs) of index two or less, which are solved using a backward differentiation formula (BDF) method.

The implementation of BDF in BondSim program is similar to DASSL, but there are some differences. Unlike DASSL that uses a fixed coefficient version of BDF, the BondSim is based on the variable coefficient form. In this way more stabile and robust DAEs solver was achieved, but at expense of more frequent re-evaluation of the partial-derivative matrices. It can deal also with discontinuous models found in many applications. More details on the methods used can be founded in (Damic \& Montgomery, 2003).

\section{NUMERICAL EXAMPLES}

\subsection{Driven rotating beam}

To clearly demonstrate physical modeling with bond graphs and applied component model approach, the torque driven rotating beam, shown in Fig.1, is taken as the first example.

Bond graph model of the rotating beam is depicted in the middle bottom of Fig. 2. The driving torque is represented by source effort SE on the left bottom in the figure, and model of the tip mass is shown on the bottom right. The rotation beam is discretized by ten finite elements (Damic, 2003) as shown in two pictures on the top of the Figure.

Material and geometrical parameter are taken from (Cai at al., 2003). The length is $L=1.8 \mathrm{~m}$, the cross sectional area is $A=2.5 \mathrm{e}-4 \mathrm{~m}^{2}$, the mass density is $\rho=2766 \mathrm{~kg} / \mathrm{m}^{3}$, the second moment of inerta is $I=1.3021 \mathrm{e}-10 \mathrm{~m}^{4}$, the modulus of elasticity is $E=6.9 \mathrm{e} 10 \mathrm{~N} / \mathrm{m}^{2}$. The radius of the hub is $0.05 \mathrm{~m}$ and its rotary inertia is $0.30 \mathrm{kgm}^{2}$. The tip mass is $0.085 \mathrm{~kg}$. Two simulations were carried out, with $T_{0}=1 \mathrm{Nm}$ and $T_{0}=7 \mathrm{Nm}$, respectively.

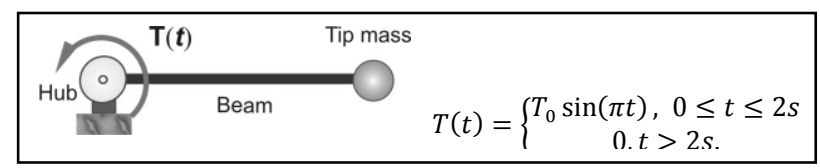

Fig. 1. The rotating beam with driving torque 


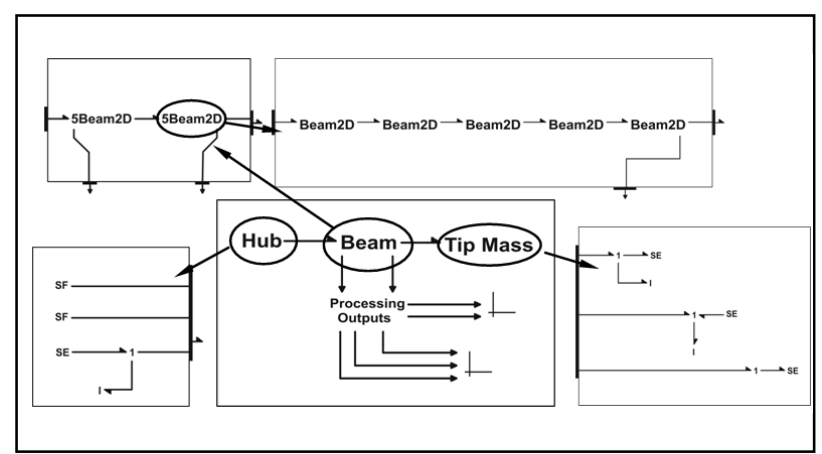

Fig. 2. Bond graph model of the rotating beam

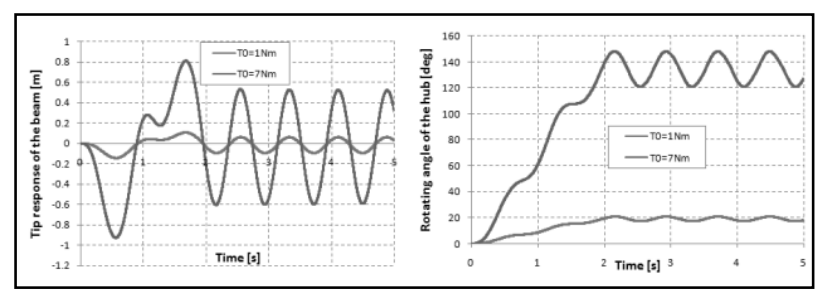

Fig. 3. Response of the beam tip

The simulation results are shown in Fig. 3 and they are in good agreement with ones reported in (Cai et al., 2005).

\subsection{Four bar mechanism}

The four bar mechanism is chosen as second numerical example, Fig. 4 a. It consists of crankshaft, connecting rod and follower, whose geometrical and material properties are given in Table1.

\begin{tabular}{|l|l|l|l|}
\hline & Crankshaft & Connecting rod & Follower \\
\hline Mass [kg] & 0.6811 & 2.474 & 1.47 \\
\hline Length [m] & 0.2 & 0.9 & 0.5196174 \\
\hline $\begin{array}{l}\text { Cross sectional } \\
\left.\text { area [m }{ }^{2}\right]\end{array}$ & $1.257 \mathrm{e}-3$ & $1.96 \mathrm{e}-3$ & $7.068 \mathrm{e}-3$ \\
\hline $\begin{array}{l}\text { Second moment of } \\
\left.\text { inertia [m }{ }^{4}\right]\end{array}$ & $1.257 \mathrm{e}-7$ & $3.068 \mathrm{e}-7$ & $3.976 \mathrm{e}-8$ \\
\hline $\begin{array}{l}\text { Modulus of } \\
\text { elasticity [N/m }\end{array}$ ] & $2.1 \mathrm{e} 11$ & $1 \mathrm{e} 9(1 \mathrm{e} 7)$ & $2.1 \mathrm{e} 11$ \\
\hline $\begin{array}{l}\text { Mass moment of } \\
\text { inertia }\left[\mathrm{kgm}^{2}\right]\end{array}$ & $2.27 \mathrm{e}-3$ & $1.669 \mathrm{e}-1$ & $3.308 \mathrm{e}-2$ \\
\hline
\end{tabular}

Tab. 1. Parameters of the four bar mechanism

Two cases are considered - in the first case the four bar mechanism is developed as a rigid body structure, and in the second as the flexible. The system level of bond graph model is depicted in the Fig.4b and has the same form in the both cases. Differences appear deeper in the next levels of the model structure. The crankshaft, connecting rod and follower are modeled as rigid bodies (Damic \& Montgomery,2003) for the rigid structure. In the second case they are developed as flexible bodies composed of 2D bond graph of finite elements beam components as follows: the crankshaft consisting of one, the connecting rod of six and the follower of four beam finite elements (Damic, 2006).

The crankshaft is driven by the torque, defined by:

$$
T(t)=\left\{\begin{array}{c}
10 \sin (3 \pi t), 0 \leq t \leq 5 / 18 \\
465,8838298 \cdot e^{-16,324194 t}, t>5 / 18
\end{array}\right.
$$

The bond graph model of the four bar mechanism is depicted in Fig 4b. The first revolute joint connects the crankshaft with the base, and it is driven by source effort (SE) component generating the torque given by Eq. (1).

The simulation results are shown in Figs. 5 and 6 and are in good agreement with the results reported in (Yakoub \& Shabana, 1999).

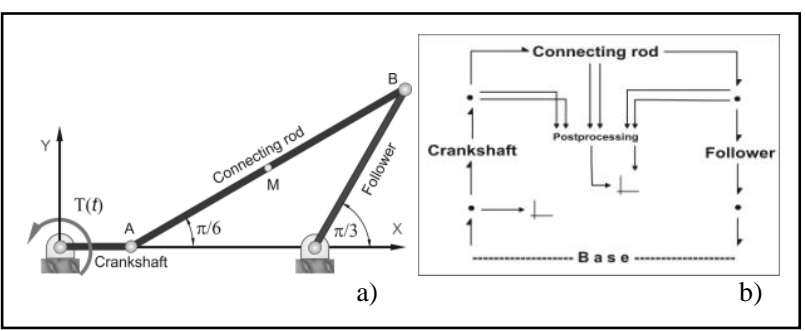

Fig. 4.The four bar mechanism: a) Scheme, b) Bond graph model

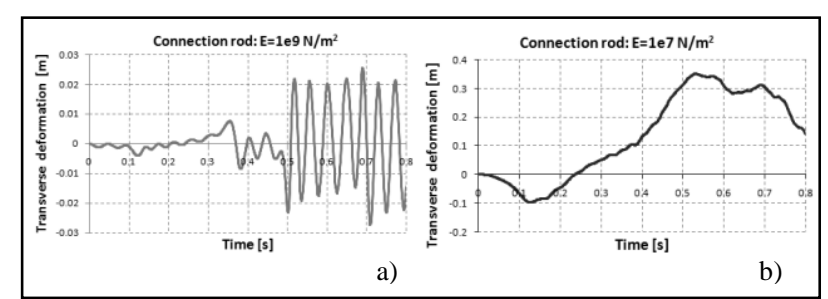

Fig. 5.Transverse deflection of the midpoint of connecting rod for: a) $E=1 \mathrm{e} 9 \mathrm{~Pa}$, b) $E=1 \mathrm{e} 7 \mathrm{~Pa}$

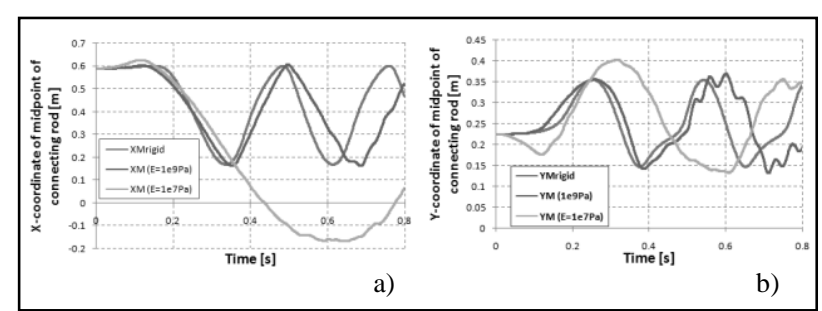

Fig. 6.Coordinates of the midpoint of connecting rod for: a) $X$ coordinate, b) Y-coordinate

\section{CONCLUSION}

The paper presents procedure for the physical modeling of mechatronics systems based on bond graph modeling. Bond graphs are chosen as powerful tool, which graphically represent power flow through systems from the different physical domains in unique way. They are used in acausal form which led to the mathematical models in form of differential-algebraic equations, which are solved using suitable solver based on backward differential formulae (BDF). Two numerical examples presented confirm the validity, accuracy and robustness of the proposed approach. It can be used with confidence in solving problems in mechatronics.

\section{REFERENCES}

Damic, V. \& Montgomery, V. (2003). Mechatronic by Bond Graphs, Springer - Verlag, ISBN 3-540-42375-3, Berlin Heidelberg

Damic, V. (2006). Modelling flexible body systems: a bond graph component model approach. Mathematical and Computer Modelling of Dynamical Systems, No.12, (175-187)

Yakoub, R.Y. \& Shabana, A.A. (1999) Use of Cholesky Coordinates and the Absolute Nodal Coordinate Formulation in Computer Simulation of Flexible Multibody Systems. Nonlinear Dynamics 20, (267-282)

Cohodar, M. Borutzky, W. \& Damic, V. (2009). Comparison of different formulation of 2D beam elements based on Bond Graph technique, Simulation Modelling Practice and Theory, $17,(107-124)$

Cai, G.P., Hong, J.Z.\&Yang, S.X. (2005) Dynamic analysis of a flexible hub-beam system with tip mass, Mechanics Research Communications, 32, (173-190)

Karnopp, D.C., Margolis, D.L. \& Rosenberg, R.C. (2000) System Dynamics, Modeling and Simulation of Mechatronic System, John Wiley\&Sons, Inc. ISBN 0-471-33301-8

P. Fritzson (2004), Principles of Object-Oriented Modelling and Simulation with Modelica 2.1, John Wiley\&Sons, Inc., ISBN 0-471-47163-1 